\section{OPEN ACCESS}

Edited by:

Jean-François Desaphy,

Università degli Studi di Bari, Italy

Reviewed by:

Matteo Elia Mangoni,

Centre National de la Recherche

Scientifique (CNRS), France

Michael E. O'Leary,

Cooper Medical School of Rowan

University, United States

${ }^{*}$ Correspondence:

Elisabetta Cerba

elisabetta.cerbai@unifi.it

${ }^{\dagger}$ Present Address:

Francesco Resta,

European Laboratory of Non Linear

Spectroscopy, Florence, Italy

Michele Melchiorre,

Laboratory for Photovoltaics, Faculty

of Science, Technology and

Communication, University of

Luxembourg, Belvaux, Luxembourg

¥These authors have contributed equally to this work

Specialty section:

This article was submitted to Pharmacology of lon Channels and Channelopathies,

a section of the journal

Frontiers in Pharmacology

Received: 05 April 2018 Accepted: 15 October 2018 Published: 08 November 2018

Citation:

Dini L, Del Lungo M, Resta F Melchiorre M, Spinelli V, Di Cesare Mannelli L, Ghelardini C, Laurino A, Sartiani L, Coppini R,

Mannaioni G, Cerbai E and Romanelli MN (2018) Selective

Blockade of HCN1/HCN2 Channels as a Potential Pharmacological Strategy Against Pain.

Front. Pharmacol. 9:1252. doi: 10.3389/fphar.2018.01252

\title{
Selective Blockade of HCN1/HCN2 Channels as a Potential Pharmacological Strategy Against Pain
}

\section{Leonardo Dini ${ }^{\ddagger}$, Martina Del Lungo ${ }^{\ddagger}$, Francesco Resta ${ }^{\dagger}$, Michele Melchiorre ${ }^{\dagger}$, Valentina Spinelli, Lorenzo Di Cesare Mannelli, Carla Ghelardini, Annunziatina Laurino, Laura Sartiani, Raffaele Coppini, Guido Mannaioni, Elisabetta Cerbai* and Maria Novella Romanelli}

Department of Neurosciences, Psychology, Drug Research and Child Health (NeuroFarBa), University of Florence, Florence, Italy

A prominent role of hyperpolarization-activated, cyclic nucleotide-gated $(\mathrm{HCN})$ channels has been suggested based on their expression and (dys)function in dorsal root ganglion (DRG) neurons, being likely involved in peripheral nociception. Using HCN blockers as antinociceptive drugs is prevented by the widespread distribution of these channels. However, tissue-specific expression of $\mathrm{HCN}$ isoforms varies significantly, $\mathrm{HCN} 1$ and HCN2 being considered as major players in DRG excitability. We characterized the pharmacological effect of a novel compound, MEL55A, able to block selectively HCN1/HCN2 isoforms, on DRG neuron excitability in-vitro and for its antiallodynic properties in-vivo. HEK293 cells expressing HCN1, HCN2, or HCN4 isoforms were used to verify drug selectivity. The pharmacological profile of MEL55A was tested on mouse DRG neurons by patch-clamp recordings, and in-vivo in oxaliplatin-induced neuropathy by means of thermal hypersensitivity. Results were compared to the non-isoform-selective drug, ivabradine. MEL55A showed a marked preference toward HCN1 and HCN2 isoforms expressed in HEK293, with respect to HCN4. In cultured DRG, MEL55A reduced $/ \mathrm{h}$ amplitude, both in basic conditions and after stimulation by forskolin, and cell excitability, its effect being quantitatively similar to that observed with ivabradine. MEL55A was able to relieve chemotherapy-induced neuropathic pain. In conclusion, selective blockade of HCN1/HCN2 channels, over HCN4 isoform, was able to modulate electrophysiological properties of DRG neurons similarly to that reported for classical $/ \mathrm{h}$ blockers, ivabradine, resulting in a pain-relieving activity. The availability of small molecules with selectivity toward HCN channel isoforms involved in nociception might represent a safe and effective strategy against chronic pain.

\footnotetext{
Keywords: neuropathic pain, dorsal root ganglion neurons, hyperpolarization-activated current, HCN channel blockade, oxaliplatin
}

\footnotetext{
Abbreviations: AP, action potential; DRG, dorsal root ganglion; HCN, hyperpolarization activated, cyclic nucleotide-gated channels; HEK293, human embryonic kidney cells; $I_{h}$, hyperpolarization-activated current; FSK, forskolin; $V_{1 / 2}$, voltage of half-maximal current activation
} 


\section{INTRODUCTION}

During the last decade, hyperpolarizing activated cyclic nucleotide-gated (HCN) channels emerged as key players controlling and facilitating neuron excitability. The $\mathrm{Na}^{+} / \mathrm{K}^{+}$ inward current flowing during $\mathrm{HCN}$ opening, $I_{\mathrm{h}}$, appears to contribute to spontaneous or ectopic firing in several tissues, including central nervous system and peripheral ganglia and nerves (recently reviewed in Sartiani et al., 2017). Among the most interesting ones, because of potential pathophysiological implications, are the nociceptive neurons whose bodies reside in the dorsal root ganglia (DRG). Recent promising findings demonstrate that $I_{\mathrm{h}}$ activation plays a facilitating role in neuropathic pain, an ill-treated disease demanding new pharmacological strategies (Tsantoulas et al., 2016). Several pieces of evidence support the over-expression and/or gain of function of HCN in animal models of chronic, neuropathic pain (Chaplan et al., 2003; Yao et al., 2003; Jiang et al., 2008). Mechanisms triggering hyperalgesia or allodynia may involve gene reprogramming (Papp et al., 2010; Descoeur et al., 2011; Schnorr et al., 2014) as well as cAMP-mediated channel gating consequent to receptor stimulation by prostaglandin E2 and substance P (Jafri and Weinreich, 1998; Momin et al., 2008; Resta et al., 2016).

A major limitation in assessing and exploiting the pharmacological impact of $\mathrm{HCN}$ modulation in pain nociception is the lack of isoform-selective compounds. The HCN family consists of four main isoforms (HCN1-4), assembling as homoor heterotetramers in the naive channels, whose biophysical properties and tissue distribution differ substantially within the nervous system and beyond (Biel et al., 2009). As a matter of fact, ivabradine, the only clinically available HCN blocker, exerts a specific, bradycardic action entailed in chronic angina and heart failure, yet unwarranted in neurological disorders (Savalieva and Camm, 2006). Ivabradine is a not-isoform selective drug and the heart rate-reducing effect has been attributed mainly to HCN4 blockade, the most highly expressed isoform in the sinoatrial node (Sartiani et al., 2017). DRG neurons express HCN isoforms unevenly, with $\mathrm{HCN} 1$ predominating in large neurons, HCN2 in small-medium ones and HCN3-4 scarcely present in all of them (Acosta et al., 2012; Schnorr et al., 2014). Altogether, these data suggest that isoform-selective HCN blockers might represent novel and safe analgesic arms against neuropathic pain (Tibbs et al., 2016; Tsantoulas et al., 2016).

The feasibility of an antinociceptive strategy based on isoform-selective HCN blockers has been confirmed by a recent paper by some of us in a rat model of neuropathic pain (Resta et al., 2018). These results were obtained using MEL57A, a phenylalkylamine structurally related to zatebradine, displaying significant selectivity for $\mathrm{HCN} 1$ over $\mathrm{HCN} 2$ and HCN4 (Melchiorre et al., 2010). Indeed, previous structureactivity studies from our lab suggested that naïve $I_{\mathrm{h}}$ current, recorded in DGR neurons, was preferentially reduced by this HCN1-selective blocker, when compared to another derivative (EC18) showing selectivity for HCN4 (Del Lungo et al., 2012). However, due to the relevant function of $\mathrm{HCN} 2$ isoform in the transmission of painful stimuli (Emery et al., 2011) and the possibility that $\mathrm{HCN} 1 / \mathrm{HCN} 2 \mathrm{co}$-assemble in heterotetramers (Chen et al., 2001), a strategy based on HCN1/HCN2 blockade (but not HCN4 blockade) might represent a promising option.

Based on preliminary proof of concept, we focused our attention on MEL55A, previously synthesized by us, showing an interesting pharmacological profile, being able to preferentially block HCN1 and HCN2 over HCN4 (Melchiorre et al., 2010). MEL55A is a reduced-flexibility analog of zatebradine, differing from the lead by the presence of a cis-butene moiety in place of the three-methylene chain, an endocyclic double bond, and a stereogenic center ( $\mathrm{R}$ configuration) close to the dimethoxyphenyl ring (Supplemental Figure 1). In the present work, we aimed to test whether the potency of this compound translates into a modulatory effect of DRG neuron excitability and underlying $I_{\mathrm{h}}$, and into an antihyperalgesic activity. These effects were compared with those of the non-selective drug, ivabradine.

\section{MATERIALS AND METHODS \\ HEK Culture}

Human embryonic kidney cells (HEK293 cells DSMZ, Braunschweig, Germany), transfected with mouse HCN1 (mHCN1), mouse HCN2 (mHCN2), and human HCN4 (hHCN4) cDNA (provided by Prof. M. Biel, LudwigMaximilians-Universität München), were cultured as described previously (Del Lungo et al., 2012) in DMEM medium (DMEM + GlutaMaxTM-I x1, Gibco, Italy) supplemented with $10 \%$ fetal bovine serum (FBS), $100 \mathrm{U} / \mathrm{ml}$ penicillin, $100 \mu \mathrm{g} / \mathrm{ml}$ streptomycin and $200 \mu \mathrm{g} / \mathrm{ml}$ geneticin (G418, Gibco, Italy) in T25 flasks and incubated at $37^{\circ} \mathrm{C}$ with $5 \% \mathrm{CO}_{2}$. At confluence (3-5 days after plating), cells were detached by using trypsinEDTA and the sedimented cells were either re-plated or used for electrophysiological measurements. Prior to electrophysiological recordings, HEK293 cells were incubated in Tyrode's solution (see Solutions) in the presence of $300 \mu \mathrm{M} \mathrm{CaCl}_{2}$ for $2-3 \mathrm{~h}$ at room temperature.

\section{Animals}

Behavioral tests were performed on male CD-1 albino mice (Envigo, Italy) weighing $\sim 22-25 \mathrm{~g}$ at the beginning of the experimental procedure, were used. In vitro measurements were performed on dorsal root ganglia (DRG) of C57black mice, 3-8 months (Envigo, Italy). Animals were housed in CeSAL (Centro Stabulazione Animali da Laboratorio, University of Florence) and used at least 1 week after their arrival. Ten mice were housed per cage (size $26 \times 41 \mathrm{~cm}$ ); animals were fed a standard laboratory diet and tap water ad libitum, and kept at $23 \pm 1^{\circ} \mathrm{C}$ with a $12 \mathrm{~h}$ light/dark cycle, light at 7 a.m. The experimental protocol was carried out after approval by the Animal Care and Research Ethics Committee of the University of Florence, Italy, under license from the Italian Department of Health and in compliance with the Directive 2010/63/EU of the European parliament and of the European Union council (22 September 2010) on the protection of animals used for scientific purposes. The ethical policy of the University of Florence complies with the Guide for the Care and Use of Laboratory Animals of the US 
National Institutes of Health (NIH Publication No. 85-23, revised 1996; University of Florence assurance number: A5278-01). Experiments involving animals have been reported according to ARRIVE guidelines [McGrath, 2015 \#485]. All efforts were made to minimize animal suffering and to reduce the number of animals used.

\section{Mouse Dorsal Root Ganglion Neurons Preparation}

Experiments were performed on dorsal root ganglia (DRG) of adult mice (C57black, 6-8 weeks). A total number of 12 mice have been used for this study. Twenty-thirty ganglia were isolated from the full length of the spinal column following removal of the spinal cord and used for primary cultures or Western blots.

For primary cultures of DRG neurons, after incubation in collagenase $(2.5 \mathrm{mg} / \mathrm{ml})$ for $1 \mathrm{~h}$ at $37^{\circ} \mathrm{C}$, ganglia were mechanically triturated with a $45 \mu \mathrm{m}$ sterile needle. The cell suspension was filtered in $40 \mu \mathrm{m}$ Nylon filter (BD Falcon) then centrifuged and re-suspended in Dulbecco's modified Eagle's medium (DMEM, Gibco, Italy) supplemented with 50 $\mathrm{U} / \mathrm{ml}$ penicillin and $0.05 \mathrm{mg} / \mathrm{ml}$ streptomycin (Invitrogen), $1 \%$ L-glutamine (Invitrogen), 10\% fetal bovine serum (FBS, Gibco, Italy), $50 \mathrm{ng} / \mathrm{ml}$ nerve growth factor (NGF, Promega) and $1.25 \mu \mathrm{g} / \mathrm{ml}$ cytosine $\beta$-D-arabinofuranoside (Ara-C, Sigma, Italy). DRG neurons were plated onto $13 \mathrm{~mm}$ borosilicate cover glass previously coated with polyL-lysine $(100 \mu \mathrm{g} / \mathrm{ml}$, Sigma, Italy) and laminin $(10 \mu \mathrm{g} / \mathrm{ml}$, Sigma, Italy). The medium was changed after $24 \mathrm{~h}$. Immunocytochemistry staining and electrophysiological recordings were made within $60-72 \mathrm{~h}$ of culture; during this time, cells develop in most cases neurites as previously reported (Fukuda, 1985).

\section{Oxaliplatin-Induced Neuropathy}

Mice treated with oxaliplatin $(2.4 \mathrm{mg} / \mathrm{kg})$ were administered i.p. on days 1-2, 5-9, 12-14 (10 i.p. injections) (Cavaletti et al., 2001; Di Cesare Mannelli et al., 2017). Oxaliplatin was dissolved in $5 \%$ glucose solution. Control animals received an equivalent volume of vehicle. Behavioral tests were performed on day 15.

\section{Cold Plate Test}

The animals were placed in a stainless-steel box $(12 \times 20 \times$ $10 \mathrm{~cm}$ ) with a cold plate as floor. The temperature of the cold plate was kept constant at $4 \pm 1^{\circ} \mathrm{C}$. Pain-related behavior (licking of the hind paw) was observed and the time (seconds) of the first sign was recorded. The cut-off time of the latency of paw lifting or licking was set at 60 s (Di Cesare Mannelli et al., 2013).

\section{Immunocytochemistry}

DRG neurons were fixed in 4\% paraformaldehyde in PBS for $15 \mathrm{~min}$ and permeabilized in $0.3 \%$ Triton X-100-PBS for $10 \mathrm{~min}$. Cells were then blocked in $1 \% \mathrm{BSA}$ for $10 \mathrm{~min}$ and incubated with rabbit anti-HCN1 [1:300], rabbit antiHCN2 [1:100], rabbit anti-HCN3 [1:25], rabbit anti-HCN4 [1:200] (Alomone Labs, Israel) antibodies overnight at $4{ }^{\circ} \mathrm{C}$ and Alexa Fluor 546 anti-rabbit (Invitrogen) secondary antibodies for $2 \mathrm{~h}$. To spot nuclei, the sample was incubated with, 4', 6-diamidino-2-phenylindole [1:1000] (DAPI, Vectashield Labs, UK) in $0.1 \%$ Tween 20 in PBS for $10 \mathrm{~min}$. Images were obtained using a fluorescence microscope (Olympus BX63, Italy) with a 20X objective and a CellSens Dimension Imaging Software (Olympus, Italy). HCN immunofluorescence in cultured DRG neurons was semi-quantitatively measured on a computer using ImageJ 1.33 image analysis software (http://rsb.info.nih.gov/ij), as described in Bigagli et al. (2018). Briefly, eight photomicrographs were randomly taken of each sample and for each cell total, membrane, or cytoplasmic HCN fluorescence was measured and expressed as pixels. These values were used to calculate the membrane/cytoplasmic relative fluorescence (\% total cell fluorescence) of $\mathrm{HCN}$ channels.

\section{Patch-Clamp Experiments}

Single cell patch-clamp experiments were performed in the whole-cell configuration using a PC-505B amplifier (Warner, Handen, CT, USA) and digitalized with Digidata $1440 \mathrm{~A}$ and Clampex 10 (Axon, Sunnyvale, CA,USA). Pipettes, resistance 3-5 M $\Omega$, were pulled from borosilicate capillaries (Harvard Apparatus Ltd, Kent, U.K.) using a two-stage horizontal puller (model P-87; Sutter Instrument, Novato, CA). Signals were sampled at $10 \mathrm{kHz}$ and low-pass filtered at $1 \mathrm{kHz}$. All recordings were made at room temperature. Cells were continuously perfused with extracellular solution using a gravity-fed perfusion system. We patched cells with a diameter $<30 \mu \mathrm{m}$ thus including the large majority of nociceptive neuron. Membrane capacitance $\left(\mathrm{C}_{\mathrm{m}}\right)$ was measured by applying a $\pm 10 \mathrm{mV}$ pulse from a holding potential of $-40 \mathrm{mV}$. Only cells showing stable $C_{m}$ and series resistance $\left(R_{s}\right)$ were included in the analysis.

Action potential (AP) recordings were performed in DRG neurons using a protocol constituted by a hyperpolarizing current step $(-100 \mathrm{pA}$, duration: $1 \mathrm{~s})$ followed by a series of depolarizing steps of increasing intensity (from 20 to $100 \mathrm{pA}$, duration: $1 \mathrm{~s}$ ), to evoke the voltage-sag and the AP, respectively.

$I_{\mathrm{h}}$ was elicited by a voltage protocol consisting of a family of hyperpolarizing steps to increasing negative potentials, from -40 to $-150 \mathrm{mV}$ from a holding potential of $-20 \mathrm{mV}$, as previously described (Del Lungo et al., 2012).

\section{Solutions for Electrophysiological Recording \\ Extracellular Solutions}

Tyrode's solution (mM): D-(+)-glucose 10, $\mathrm{NaCl} \mathrm{140,} \mathrm{KCl} 5.4$, $\mathrm{MgCl}_{2}$ 1.2, $\mathrm{CaCl}_{2}$ 1.8, HEPES-NaOH 5.0, ( $\mathrm{pH}$ 7.3); modified Tyrode's solution to measure $I_{\mathrm{h}}$ in HEK cells: Tyrode's solution with $25 \mathrm{mM} \mathrm{KCl}$; modified Tyrode's solution to measure $I_{\mathrm{h}}$ in DRG neurons: Tyrode's solution with (mM): $\mathrm{BaCl}_{2} 2, \mathrm{MnCl}_{2} 2$, 4-aminopyridine 0.5 , and $\mathrm{KCl} 25$. Intracellular solution $(\mathrm{mM})$ : $\mathrm{K}$ aspartate 130; $\mathrm{Na}_{2}$-ATP 5, $\mathrm{MgCl}_{2} 2, \mathrm{CaCl}_{2}$ 5, EGTA 11, HEPES$\mathrm{KOH} 10$ (pH 7.2; pCa 7.0).

MEL55A (3-[(2Z)-4-\{[(2R)-2-(3,4-dimethoxyphenyl)propyl] (methyl)amino\}but-2-en-1-yl]-7,8-dimethoxy-2,3-dihydro-

1H-3-benzazepin-2-one hydrochloride, see the formula in 
Supplemental Figure 1) was synthesized as reported previously (R5; Melchiorre et al., 2010). MEL55A and ivabradine solutions were obtained from stock solutions $\left(10^{-2} \mathrm{M}\right)$ in water and diluted in the different experimental solution to reach the desired final concentration.

\section{Data Analysis and Statistics}

Current amplitude was obtained by fitting the time-dependent component of $\mathrm{I}_{\mathrm{h}}$ current tracings from the peak initial current to the steady-state current with a mono- (in HEK) or bi-exponential function (in DGR neurons), which gave the best fitting results. In

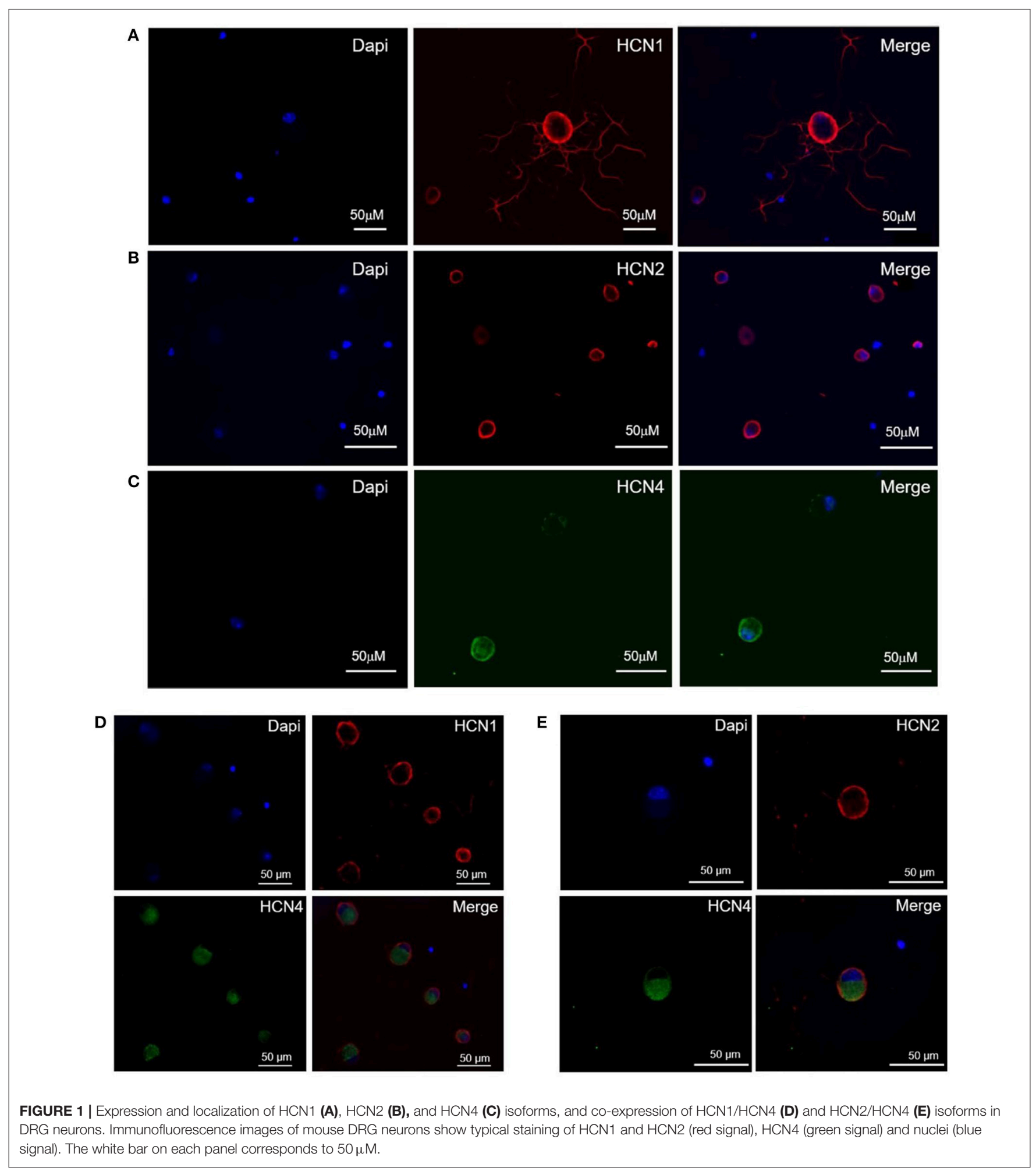


case of bi-exponential function, the time constant tau reported in Figures refers to the largest current component measured by the fitting. Current density was calculated as the difference between the peak current at the beginning of the hyperpolarizing step and the steady-state current, normalized to membrane capacitance. From the current-voltage relationship, specific current conductance was determined for each cell according to the equation:

$$
G_{H C N}=I \times\left(V_{m}-V_{r e v}\right)^{-1}
$$

where $G_{H C N}$ is the conductance ( $\mathrm{pS} / \mathrm{pF}$ ) calculated at membrane potential $V_{m}, I$ the current density $\left(\mathrm{pA} / \mathrm{pF}\right.$ ), and $V_{\text {rev }}$ (reversal potential) is calculated from the analysis of tail currents (Cerbai et al., 1994). The effect of forskolin on $I_{\mathrm{h}}$ activation, in the absence and presence of $I_{\mathrm{h}}$ blockade, was evaluated by tail current analysis, using a two-step protocol consisting of a first step varying from -50 to $-130 \mathrm{mV}$, eliciting fractional $I_{\mathrm{h}}$, and a second step to $-130 \mathrm{mV}$ to activate the residual current. Activation curves of $I_{\mathrm{h}}$ were fitted with Boltzmann function

$$
G_{H C N}=\operatorname{gmax} \times\left\{1+\exp \left[\left(V_{1 / 2}-V_{m} / k\right)\right]\right\}^{-1}
$$

where $V_{1 / 2}(\mathrm{mV})$ is the half-activation potential and $k(\mathrm{mV})$ is the slope factor.

Concentration-effect curves were obtained at three different concentrations $(1,10$, and $30 \mu \mathrm{M})$ and fitted to a Hill distribution

$$
y=E_{\max } \times\left[x_{n} \times\left(k_{n}+x_{n}\right)^{-1}\right]
$$

where $E_{\text {max }}$ is the maximum effect, $k$ corresponds to the concentration for half-maximal blocking effect $\left(\mathrm{IC}_{50}\right), x$ is the drug concentration and $n$ is the Hill coefficient.

Analysis of electrophysiological data and curve fitting was performed by using OriginPro 2015 (OriginLab Corporation, USA). Statistical comparison was performed with one-way ANOVA; the effect of compounds on $I_{\mathrm{h}}$ activation curve was evaluated by Multiple $t$-test (GraphPad PRISM v.5, USA). Behavioral measurements were performed on 12 mice for each treatment carried out in 2 different experimental sets. The analysis of variance of behavioral data was performed by one way ANOVA, a Bonferroni's significant difference procedure was used as post-hoc comparison. Data were analyzed using the "Origin 9" software (OriginLab, Northampton, USA).

All data are expressed as mean \pm SEM unless indicated. A probability value $<0.05$ was considered significant.

\section{RESULTS}

\section{Expression and Localization of $\mathrm{HCN}$ Isoforms in Mouse DRG Neurons}

The population of DRG neurons in culture typically consists of cells with different dimensions for which, according to data in literature (Acosta et al., 2012; Schnorr et al., 2014), the proportion of $\mathrm{HCN}$ isoforms may vary depending on size. We observed that immunoreactivity for all three isoforms was present in DRG neurons (Figures 1A-C); however, their sublocalization was apparently different. The semiquantitative analysis reported

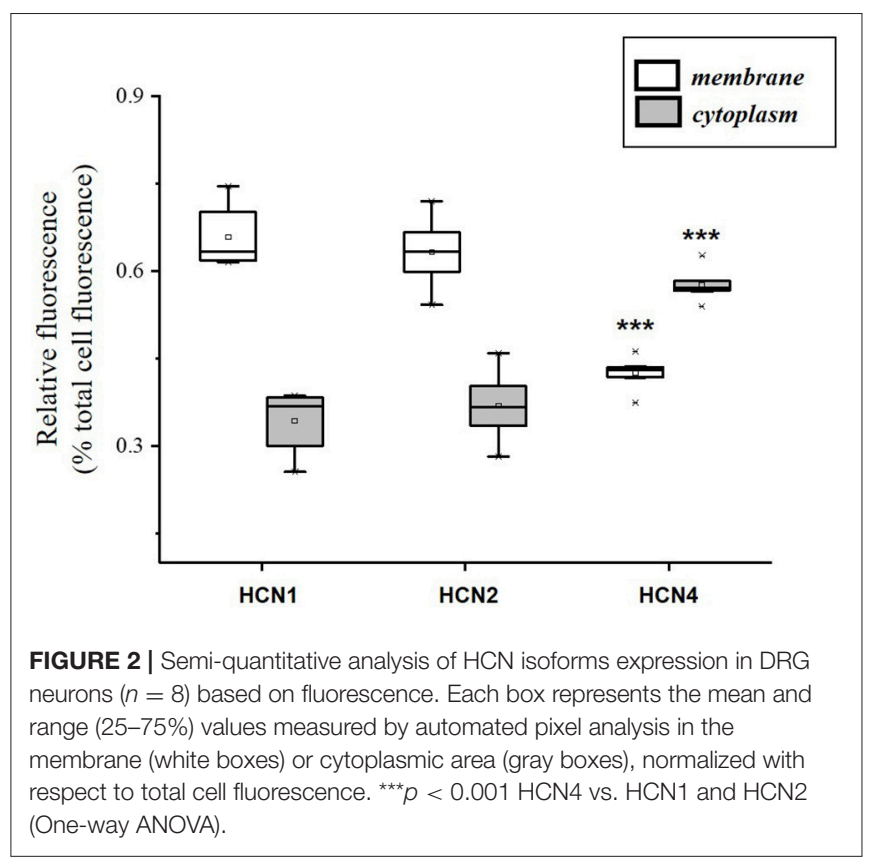

in Figure 2 shows that $\mathrm{HCN} 1$ and $\mathrm{HCN} 2$ have a prevalent membrane localization; as for HCN4, immunoreactivity was detected at membrane as well as intracellularly, the proportion between the two compartments being significantly different from the other two isoforms. Co-localization experiments revealed a simultaneous expression of HCN1-HCN4 or HCN2-HCN4 in neurons, $\mathrm{HCN} 1$ and $\mathrm{HCN} 2$ isoforms showing prevalent membrane localization (Figures 1D,E).

\section{Isoform-Selective Effect of MEL55A in HEK293 Expressing HCN}

Based on expression profile and localization of $\mathrm{HCN}$ isoforms in DRG neurons and previously reported effect on maximal current in heterologously expressed channels (Melchiorre et al., 2010), we further assessed the properties of MEL55A ( $R$-enantiomer, Supplemental Figure 1) in HEK293 cells at physiologically relevant potentials. Figure $3 \mathrm{~A}$ shows the effect of $10 \mu \mathrm{M}$ MEL55A on current evoked by hyperpolarizing step at $-80 \mathrm{mV}$ for the three isoforms, whose properties $\left(V_{1 / 2}\right.$ and time constant of activation, tau) are reported in Figure $3 \mathrm{C}$. The percentage blockade of HCN current measured at $-70,-80$, and $-90 \mathrm{mV}$ with increasing concentrations of $\operatorname{MEL55A}(1,10$, and $30 \mu \mathrm{M})$ was significantly higher for $\mathrm{HCN} 1$ and $\mathrm{HCN} 2$ with respect to HCN4 at any concentration, with the exception of one point (HCN2 at $-90 \mathrm{mV}$ ).

\section{$I_{h}$ Blockade by MEL55A in DRG Neurons}

Figure 4 shows typical current tracings evoked by hyperpolarizing steps in the absence and presence of 10 or $30 \mu \mathrm{M}$ MEL55A. Average activation curve (Figure 4C) shows that MEL55A reduced $I_{\mathrm{h}}$ amplitude significantly $(p<0.0001$, CTR vs all tested concentration) at any voltage step and in a concentration-dependent fashion. The effect was even more 
A

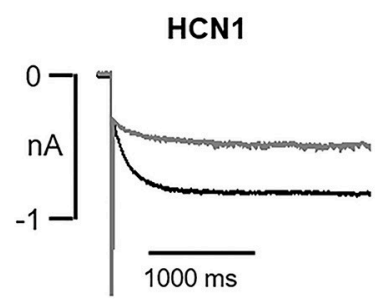

B

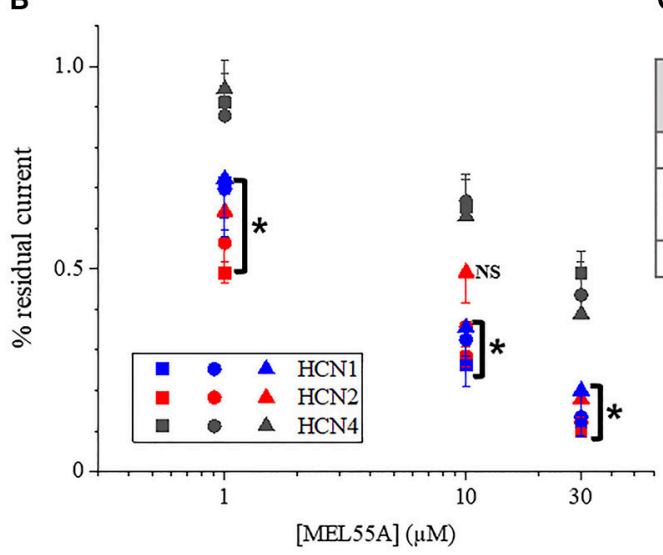

HCN2

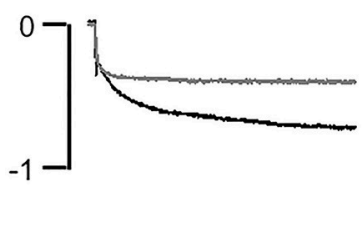

HCN4

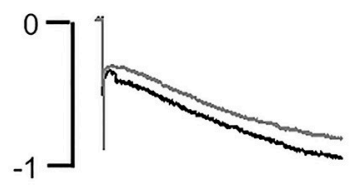

C

\begin{tabular}{|c|c|c|c|c|c|}
\hline & \multirow{2}{*}{$\begin{array}{c}V_{1 / 2} \\
(m V)\end{array}$} & \multirow{2}{*}{$\begin{array}{c}k \\
(\mathrm{mV})\end{array}$} & \multicolumn{3}{|c|}{ tau (ms) } \\
\hline & & & @-70mV & @-80mV & @-90mV \\
\hline HCN1 & $-67.7 \pm 3.1$ & $12.2 \pm 1.5$ & $363 \pm 182$ & $305 \pm 84$ & $278 \pm 60$ \\
\hline HCN2 & $-81.6 \pm 2.5$ & $9.4 \pm 1.1$ & $1345 \pm 445$ & $855 \pm 294$ & $511 \pm 134$ \\
\hline HCN4 & $-84.0 \pm 2.9$ & $10.7 \pm 1.8$ & $969 \pm 56$ & $886 \pm 52$ & $793 \pm 44$ \\
\hline
\end{tabular}

FIGURE 3 | Effect of MEL55A on HCN isoforms heterologously expressed in HEK293 cells. (A) Representative tracings elicited by voltage steps to -80 mV, in the absence (black line) and presence (gray line) of $10 \mu \mathrm{M}$ MEL55A. (B) concentration dependent blockade of HCN isoforms by 1,10 , and $30 \mu \mathrm{M}$ measured at $-70 \mathrm{mV}$ (squares), $-80 \mathrm{mV}$ (circles), and $-90 \mathrm{mV}$ (triangles). Each point represents the mean \pm S.E.M of 5-6 cells. ${ }^{*} p<0.05$ HCN1 or HCN2 vs. HCN4 by using One-way ANOVA Multiple comparison test. (C) Basic properties of activation curve for the three HCN isoforms heterologously expressed in HEK293 cells.

evident at less negative step potentials; at $-80 \mathrm{mV}$ (dashed line), MEL55A blocked about $80 \%$ of the available current, thus reducing $I_{\mathrm{h}}$ density from $0.28 \pm 0.04 \mathrm{pS} / \mathrm{pF}$ in control $(n=11)$ to $0.06 \pm 0.01 \mathrm{pS} / \mathrm{pF}(n=7)$ at $10 \mu \mathrm{M}$ and $0.06 \pm 0.04 \mathrm{pS} / \mathrm{pF}$ $(n=7)$ at $30 \mu \mathrm{M}$. With $100 \mu \mathrm{M}$ MEL55A $(n=7)$, no residual current was evoked by steps positive to $-100 \mathrm{mV}$. At $-120 \mathrm{mV}$, the percentage reduction of available current was $26 \%$ for $10 \mu \mathrm{M}$ MEL55A, $46 \%$ for $30 \mu \mathrm{M}$, and $85 \%$ for $100 \mu \mathrm{M}(p<0.0001)$ (CTR: $0.85 \pm 0.02 \mathrm{pS} / \mathrm{pF}, n=11 ; 0.63 \pm 0.03 \mathrm{pS} / \mathrm{pF}, n=7 ; 0.46$ $\pm 0.07 \mathrm{pS} / \mathrm{pF}, n=7 ; 0.13 \pm 0.05 \mathrm{pS} / \mathrm{pF}, n=7$, in the presence of 10,30 , and $100 \mu \mathrm{M}$ MEL55A, respectively).

Due to a more pronounced effect at less negative potentials, the activation curve was apparently shifted to the left. The voltage of half-maximal activation $\left(\mathrm{V}_{1 / 2}\right)$ was $-92.7 \pm 0.9 \mathrm{mV}(n=11)$ in control, $-101.4 \pm 1.2 \mathrm{mV}(n=7, p<0.0001),-108 \pm 1.8 \mathrm{mV}(n$ $=7, p<0.0001)$, and $-122 \pm 2.7 \mathrm{mV}(n=7, p<0.0001)$ in the presence of 10,30 , and $100 \mu \mathrm{M}$ MEL 55A, respectively.

$\mathrm{HCN}$ isoforms have different kinetics and voltage-dependent properties, according to data obtained from homotetramer channels expressed in heterologous cells (Altomare et al., 2003; Stieber et al., 2004; Baruscotti et al., 2005). The time constant of activation of $I_{\mathrm{h}}$ in the absence and presence of MEL55A is shown in Figure 4D. The apparent shift of activation curve caused by MEL55A might be consistent with a more pronounced effect on $\mathrm{HCN} 1$ isoform, which activates at less negative potentials and exhibits a faster kinetics (see Figures 3A,C). In agreement with this hypothesis, current kinetics of activation was also slowed down by MEL55A (Figure 4D); of note, HCN1 and HCN2 also have a faster kinetics with respect to HCN4. At $-120 \mathrm{mV}$, time constant of activation $(\tau)$ was $162 \pm 22 \mathrm{~ms}$ in CTR, $173 \pm 14 \mathrm{~ms}$, $344 \pm 50 \mathrm{~ms}(p<0.01)$ and $473 \pm 107 \mathrm{~ms}(p<0.01)$ in the presence of 10,30 , and $100 \mu \mathrm{M}$ MEL55A, respectively.

Figure 5 shows current tracings and activation curves obtained in the absence and presence of 10 and $30 \mu \mathrm{M}$ ivabradine, a non-isoform-selective blocker of HCN. At the lowest concentration ( $10 \mu \mathrm{M}$, Figure $5 \mathrm{C})$, ivabradine showed a similar qualitative effect but less marked current blockade (45\% reduction at $-80 \mathrm{mV})$ and $\mathrm{V}_{1 / 2}$ was unchanged $(-95.5 \pm 1.19 \mathrm{mV}$ in CTR, $n=12$ vs. $-95 \pm 1.3 \mathrm{mV}$ with IVA, $n=9$ ). The kinetics of current activation was not significantly affected (Figure 5D). Average membrane capacitance of tested neurons was $55 \pm 9 \mathrm{pF}$, in line with data from cells cultured in similar conditions ( $\mathrm{Li}$ and Baccei, 2014).

\section{Effect of $I_{h}$ Blockade on DRG Membrane (Voltage Sag)}

In DRG neurons, $I_{\mathrm{h}}$ likely plays a role in controlling membrane excitability (Tsantoulas et al., 2016; Sartiani et al., 2017); a characteristic of $I_{\mathrm{h}}$ activation is the occurrence of a "voltage sag" upon hyperpolarization, due to $\mathrm{Na}^{+}$entry through $\mathrm{HCN}$ channels (Resta et al., 2016).

Figure 6 shows examples of voltage sag generated by $I_{\mathrm{h}}$ in response to $1000 \mathrm{~ms}$ hyperpolarizing current steps (to $-100 \mathrm{pA}$ ) 


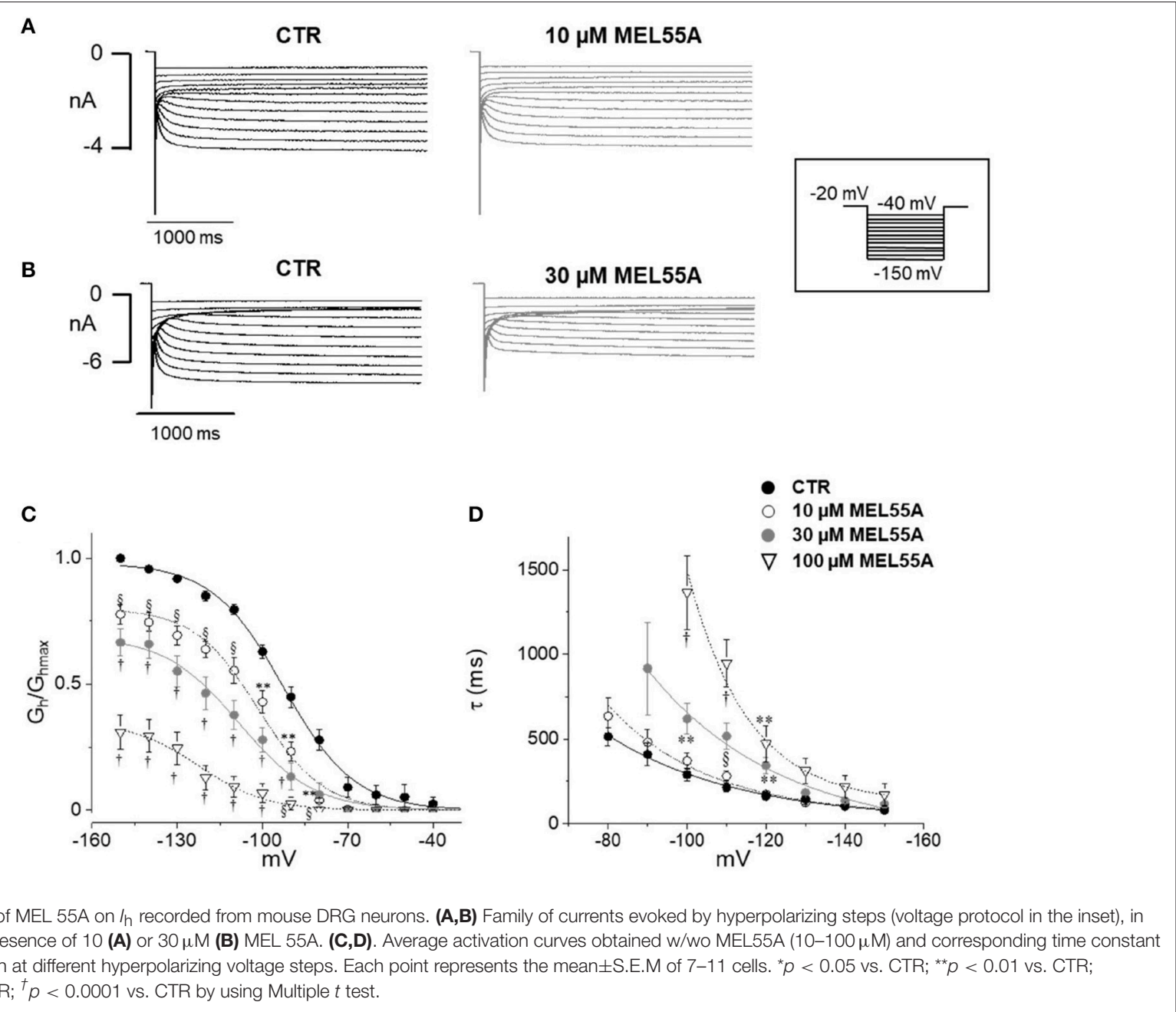

in the absence and presence of MEL55A (10 and $30 \mu \mathrm{M})$ or ivabradine $(30 \mu \mathrm{M})$. Consistent with $I_{\mathrm{h}}$ blockade at voltage steps around the "sag" membrane potential, current-clamp recordings showed a marked reduction of the amplitude of the voltage sag in the presence of MEL55A tested at $30 \mu \mathrm{M}$. We quantified contribution of HCN channel activity by measuring the percentage sag ratio, i.e., the difference between the peak voltage $\left(\mathrm{V}_{\text {peak }}\right)$ and steady-state voltage $\left(\mathrm{V}_{\mathrm{ss}}\right)$, normalized to $\mathrm{V}_{\text {peak. }}$. The voltage sag ratio decreased from $22.7 \pm 3.6$ to $14.0 \pm 2.6 \%$ in the presence of $30 \mu \mathrm{M}$ MEL55A $(n=12$, $p<0.05)$. Similar effects were observed with ivabradine at the same concentration $(26.4 \pm 5.2 \%$ in CTR vs. $12.0 \pm 2.1 \%$ with $30 \mu \mathrm{M}$ IVA, $n=12$ ).

\section{MEL55A Counteracts the Effect of cAMP on $I_{h}$ Activation}

According to the literature (see Sartiani et al., 2017 for a review) and previously published data from some of us (Resta et al., 2018), the contribution of $I_{\mathrm{h}}$ to DRG neuron excitability is amplified by pathological conditions able to modify channel expression or properties, e.g., by increasing intracellular cyclic AMP levels. When challenged with $30 \mu \mathrm{M}$ forskolin (FSK), a direct activator of adenylate cyclase, the activation curve of $I_{\mathrm{h}}$ was shifted rightward, $\mathrm{V}_{1 / 2}$ being $-85.4 \pm 1.9 \mathrm{mV}$ in CTR vs. $-78.2 \pm 1.8 \mathrm{mV}$ with FSK $(n=11, p<0.05)$, with no significant changes in maximum current (CTR $649 \pm 143$ pA; FSK $600 \pm$ $139 \mathrm{pA}$ ) (Figures 7A,B). Likewise, this result suggests a relevant contribution of HCN2 isoform to $I_{\mathrm{h}}$ current recorded in our DGR neurons (Resta et al., 2016). In these conditions, as a proof of concept, we tested the effect of $30 \mu \mathrm{M}$ MEL55A, i.e., a concentration able to block $I_{\mathrm{h}}$ almost completely at relevant potentials (Figure 5) and showing a moderate yet statistically significant selectivity toward $\mathrm{HCN} 1 / \mathrm{HCN} 2$ isoforms compared to HCN4 (Figure 3B). At this concentration, MEL55A was able not only to reduce maximum $I_{\mathrm{h}}$ amplitude $(407 \pm 104 \mathrm{pA}$, $\mathrm{p}<0.05$ vs. CTR and FSK), but also to revert the positive shift of $\mathrm{V}_{1 / 2}(-85.7 \pm 2.1 \mathrm{mV}, p<0.01$ vs. FSK). Figure $7 \mathrm{C}$ reports typical current tracings measured during a double step protocol, evoked by hyperpolarization to $-90 \mathrm{mV}$ followed by a brief step to $-130 \mathrm{mV}$. Similar results were observed with ivabradine (Figure 8). 

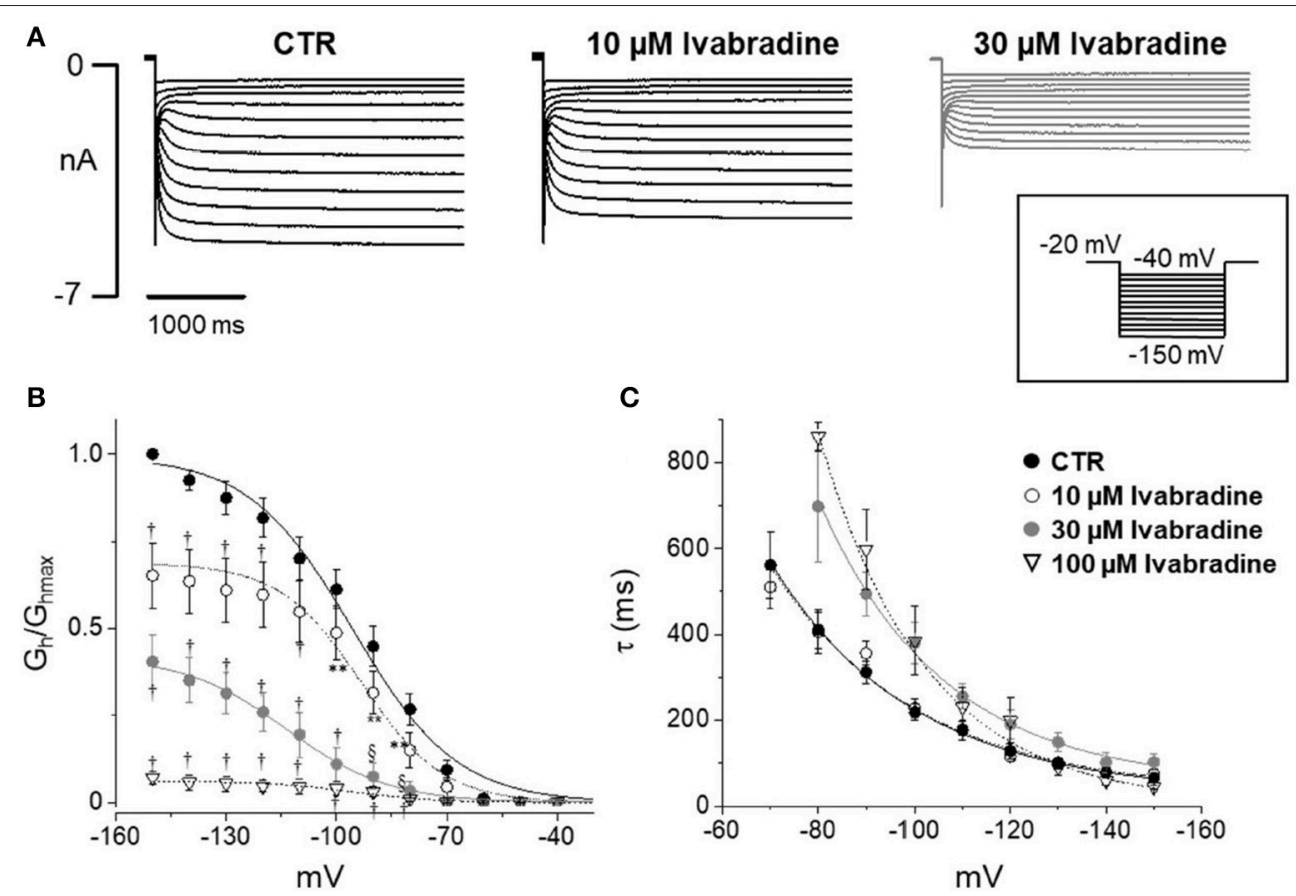

C

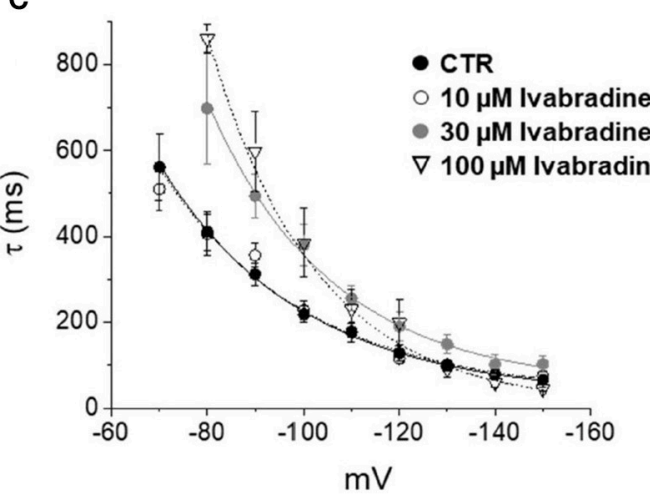

FIGURE 5 | Effect of ivabradine on /h recorded from mouse DRG neurons. (A) Typical current recordings in the absence or presence of 10 and $30 \mu M$ IVA; (B,C) Average activation curves and corresponding time constant for activation obtained w/wo ivabradine at different concentrations. Each point represents the mean \pm S.E.M of $9-12$ cells. ${ }^{\star} p<0.05$ vs. CTR; ${ }^{* \star} p<0.01$ vs. CTR; $\$ p<0.001$ vs. CTR; ${ }^{\dagger} p<0.0001$ vs. CTR by using Multiple $t$ test.

\section{Effect of MEL55A on Neuron Discharge}

In current-clamp configuration, application of depolarizing steps evoked spontaneous action potential (AP), followed by quiescence (Figure 9A, top); superfusing with FSK-at the same concentration able to cause a rightward shift of $I_{\mathrm{h}}$ activationled to the appearance of a series of spontaneous APs upon application of an identical depolarizing step (medium panel); $30 \mu \mathrm{M}$ MEL55A on top of FSK reduced the number of APs (lower panel). The effect was consistently observed in 14 cells (Figure 9B).

\section{Effect of MEL55A on Oxaliplatin-Induced Neuropathy}

The ability of MEL55A to reduce hypersensitivity was tested in a mouse model of oxaliplatin-induced neuropathy. Twoweeks treatment with oxaliplatin progressively decreased the mice pain threshold as evaluated by the cold plate test. The licking latency decreased to $13.8 \pm 1.1 \mathrm{~s}$ in comparison to vehicle-treated animals $(23.2 \pm 1.0 \mathrm{~s}$, Table 1$)$. The acute effect elicited by a single i.p. administration of MEL55A ( $30 \mathrm{mg} \mathrm{kg}^{-1}$ ) was evaluated on day 15. MEL55A induced a pain relief, lasting $45 \mathrm{~min}$ and peaking at $30 \mathrm{~min}$, time at which the licking latency was restored close to control value. Under the same conditions, the effect of the same dose of ivabradine ( $30 \mathrm{mg} \mathrm{kg}$ i.p.) was shorter, disappearing after $30 \mathrm{~min}$. In contrast, the compound EC18 (Del Lungo et al., 2012), previously characterized as HCN4-preferring compound, was inactive in this test (Table 1). All compounds did not modify the normal pain threshold of vehicle-treated animals (Table $\mathbf{1}$ ).

\section{DISCUSSION}

Our results demonstrate that MEL55A, exhibiting preferential blockade of heterologously expressed $\mathrm{HCN} 2$ and $\mathrm{HCN} 1$ isoforms, could diminish the amplitude of $I_{\mathrm{h}}$, either in basic conditions and after stimulation by intracellular cAMP, and reduce cell excitability in mouse DRG neurons in culture. To our knowledge, this is the first demonstration that preferential blockade of HCN2 and HCN1 channels, over HCN4 isoform, was able to modulate the electrophysiological properties of DRG neurons similarly to that reported for classical $I_{\mathrm{h}}$ blockers, ZD7288 and ivabradine (Chaplan et al., 2003; Descoeur et al., 2011).

MEL55A is an analog of zatebradine characterized by reduced-flexibility and a stereogenic center ( $\mathrm{R}$ configuration) close to the dimethoxyphenyl ring whose synthesis and preliminary screening in HEK cells has been previously described (R5 in Melchiorre et al., 2010). A preferential HCN1/HCN2 blockade was observed on heterologously re-expressed, fully activated current $(-120 \mathrm{mV})$ and further suggested by stereoselectivity: in fact, the blocking potency of the S-enantiomer on maximally activated $I_{\mathrm{h}}$ (i.e., at $-120 \mathrm{mV}$ ) was quantitatively smaller and similar for the three HCN isoforms. Thus, we extended previous results and showed that MEL55A preferentially blocked HCN1/HCN2 isoforms over HCN4 also when tested on heterologously re-expressed current evoked by steps at physiologically relevant potentials $(-70$ to $-90 \mathrm{mV})$. This observation prompted us to naïve cells where these isoforms may play a relevant physiological 

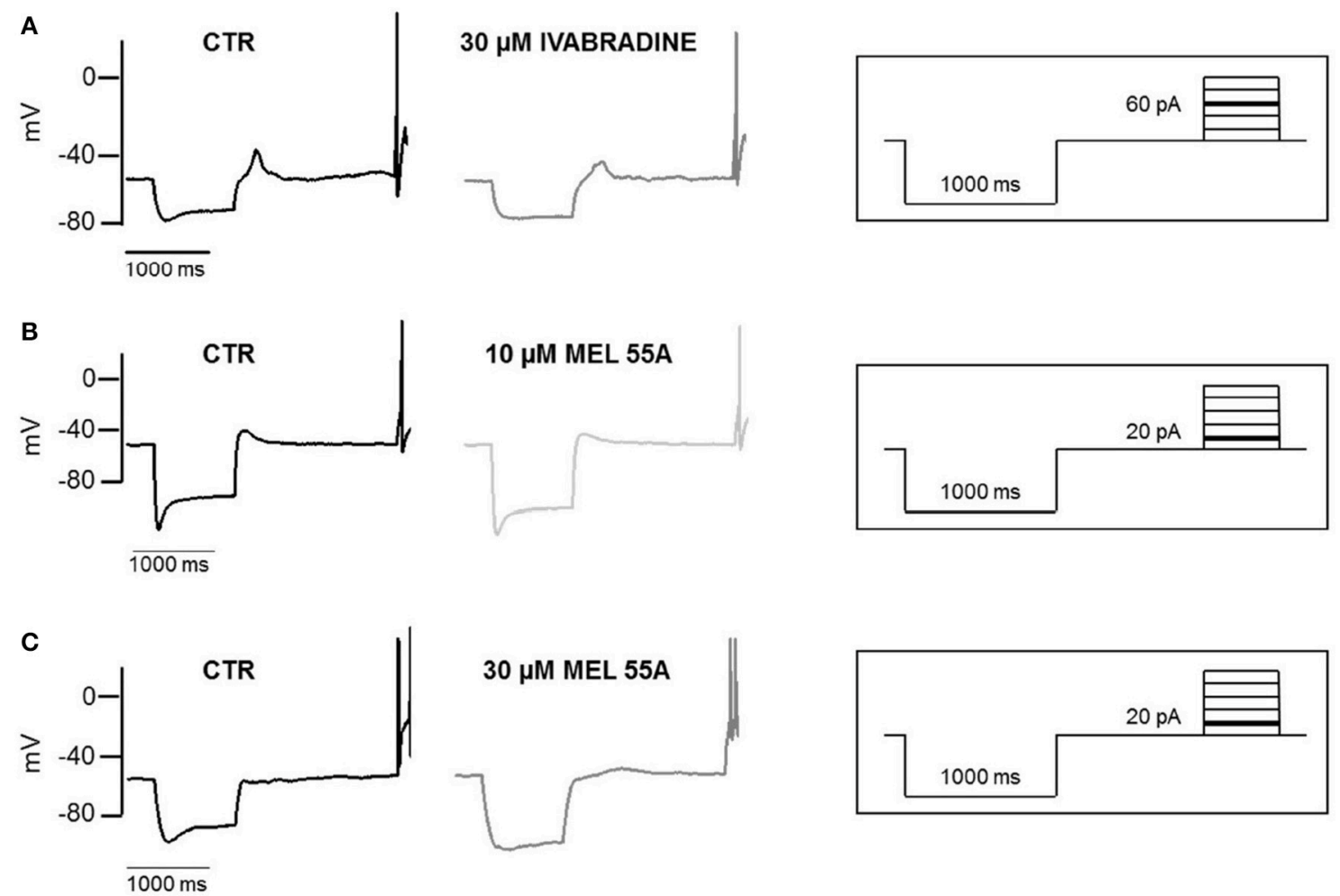

FIGURE 6 | Effect of IVA and MEL55A on membrane potential and voltage sag in DRG neurons. Voltage sag and action potential evoked by a hyperpolarizing current $(-100 \mathrm{pA})$ followed by a depolarizing pulse (60 pA) in control conditions and in the presence of $30 \mu \mathrm{M}$ ivabradine (A) $10 \mu \mathrm{M}$ MEL55A (B) and $30 \mu \mathrm{M}$ MEL55A (C). Current protocols are shown in inset on the right of corresponding traces.

role in controlling excitability, i.e., DRG neurons (Tibbs et al., 2016).

According to our hypothesis, MEL55A reduced $I_{\mathrm{h}}$ amplitude in DRG neurons; concurrently, when tested at $30 \mu \mathrm{M}$, it halved the amplitude of voltage sag upon hyperpolarization and inhibited neuron excitability following depolarizing steps. In line with published data (Young et al., 2014), the effect on $I_{\mathrm{h}}$ was similar to that observed with ivabradine.

Translating results on $\mathrm{HCN}$ isoforms expressed in recombinant systems to naïe cells is always difficult for several reasons. First, h-channels in DRG neurons are likely heterotetramers, although the exact stoichiometry is uncertain, while only homotetramers are expressed in our HEK cells. Second, the functional and pharmacological properties of naïve $I_{\mathrm{h}}$ also depends on post-translational channel modification including membrane translocation, presence of beta subunits (e.g., MiRP1) and co-localization with caveolin-3, which modify channel properties, in particular voltage-dependence and current amplitude (see Sartiani et al., 2017 for a comprehensive review).

In our cultured DGR neurons, also in agreement with data in literature (Acosta et al., 2012), we observed a well-defined expression and membrane localization for HCN1 and HCN2 isoforms by immunostaining and semi-quantitative analysis, while HCN4 staining was mainly detected at cytoplasmic level. As for electrophysiological properties, time constant (tau) for $I_{\mathrm{h}}$ activation measured in DRG neurons at $-100 \mathrm{mV}$ was around $250 \mathrm{~ms}$, similar to values reported in previous studies in the same cells (Gao et al., 2012). Interestingly, tau value lays midway those measured for heterologously expressed HCN1 and HCN2 isoforms in our experimental conditions (at $-100 \mathrm{mV}$ : $182 \pm$ 29 and $312 \pm 59 \mathrm{~ms}$, respectively; tau for HCN4: $690 \pm 39 \mathrm{~ms}$ ). Overall, the electrophysiological properties of $I_{\mathrm{h}}$ measured in our experimental conditions are consistent with $\mathrm{HCN} 1 / \mathrm{HCN} 2$ characteristics in recombinant systems. Although the functional presence of HCN4 in naïve h-channels cannot be ruled out completely and a detailed characterization of $\mathrm{HCN}$ isoform contribution to $I_{\mathrm{h}}$ was beyond the scope of this study, it is worth to recall that the selective HCN4 blocker, EC18, was completely ineffective on $I_{\mathrm{h}}$ measured in DRG neurons in the same conditions up to a concentration of $100 \mu \mathrm{M}$ (Del Lungo et al., 2012).

The "apparent" negative shift of activation curve caused by MEL55A observed for $I_{\mathrm{h}}$ in DRG neurons is not completely surprising, if one recalls the so-called "current dependence" of HCN blockade originally reported for ivabradine (Bucchi et al., 2002). Briefly, blockade by ivabradine is removed when current flows inwardly through the open f-channels, while develops rapidly when channels deactivate at depolarized voltages. Channel unblock during persistent opening (i.e., hyperpolarization) has also been observed (Bucchi et al., 2006). 


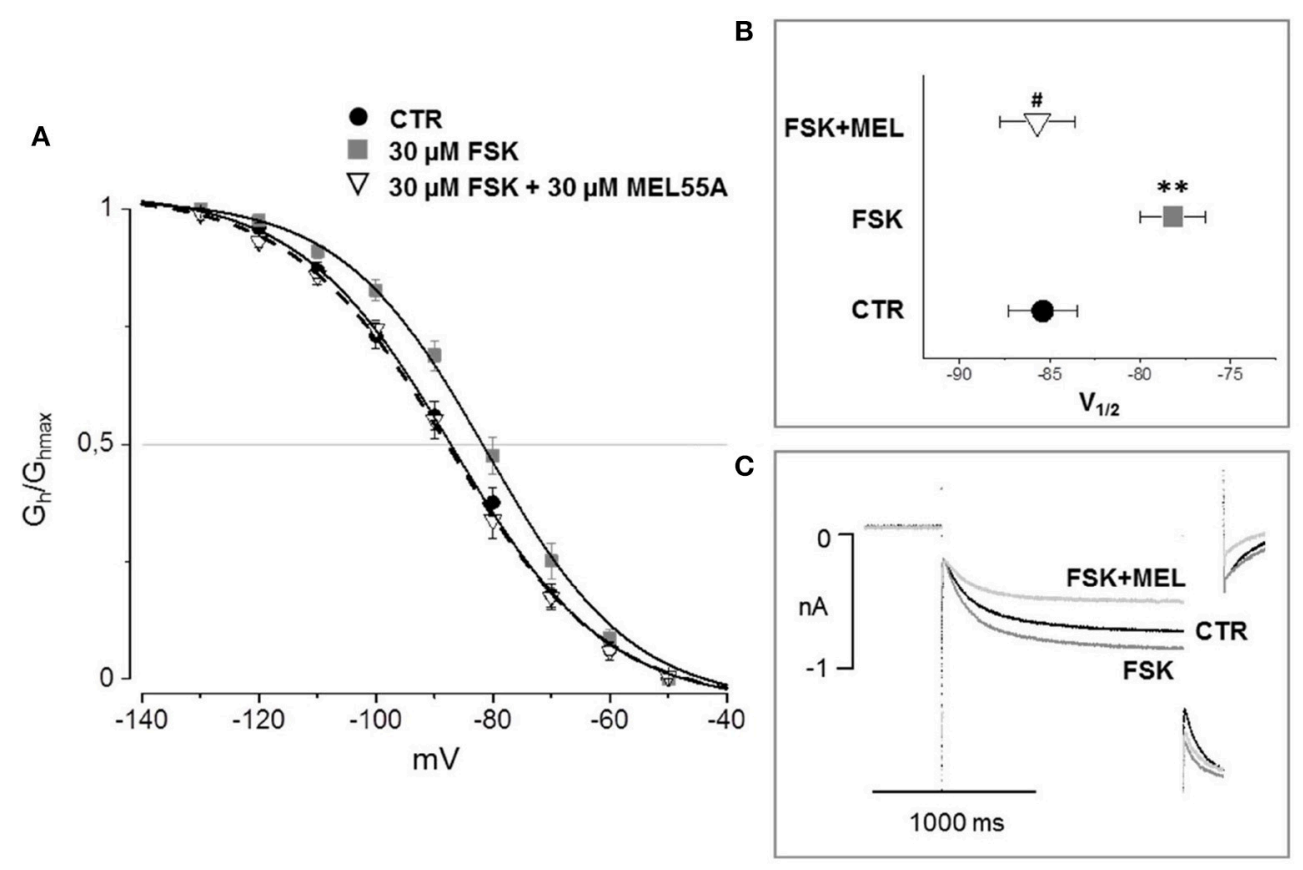

FIGURE 7 | Effect of MEL 55A on /h amplified by FSK in DRG neurons. Average activation curves (A) obtained in control (solid circles), with FSK (gray squares) and with FSK + MEL55A $30 \mu \mathrm{M}$ (open triangles) and corresponding $V_{1 / 2}$ (B,C): typical current tracings measured during a double step protocol, evoked by hyperpolarization to $-90 \mathrm{mV}$ followed by a brief step to $-130 \mathrm{mV} . N=11,{ }^{\star \star} p<0.01 \mathrm{vs}$. CTR; $\# p<0.01 \mathrm{vs}$. FSK.

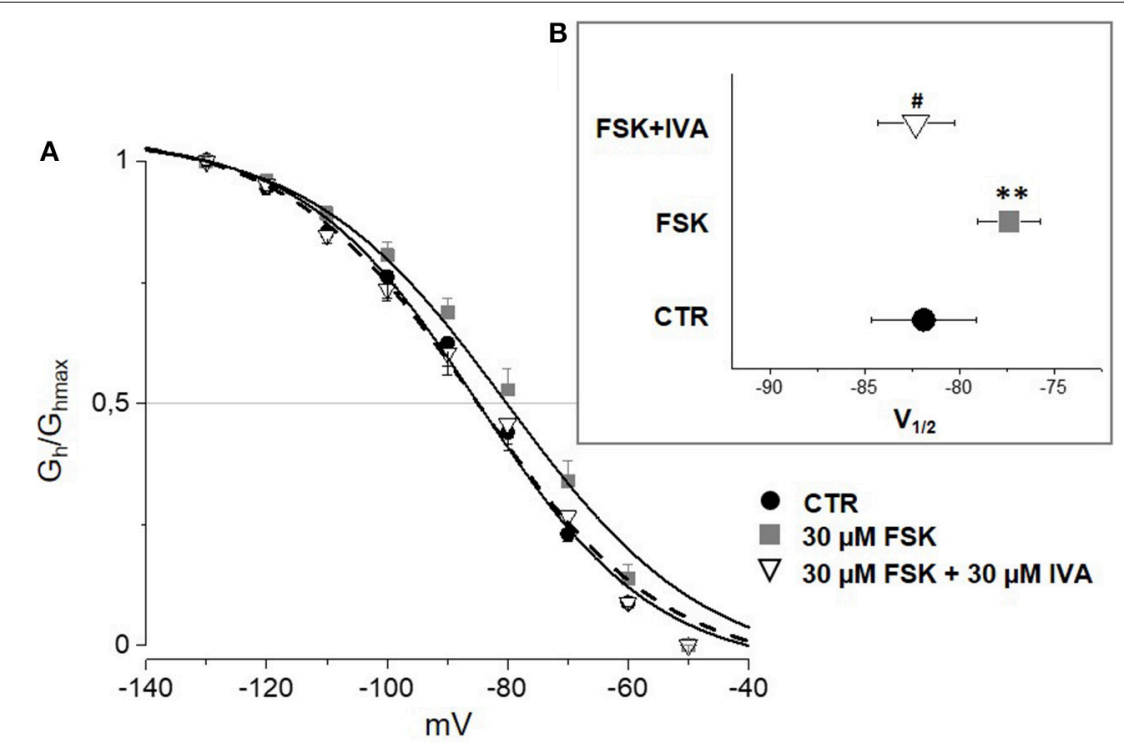

FIGURE 8 | Effect of ivabradine (IVA) on $/ \mathrm{h}$ amplified by FSK in mouse DRG neurons. Average I-V curves (A) obtained in control (solid circles), with FSK (gray squares) and with FSK+ $30 \mu \mathrm{M}$ ivabradine (open triangles) and corresponding $V_{1 / 2}$ (B). $N=10,{ }^{* \star} p<0.01 \mathrm{vs.} \mathrm{CTR;} \# p<0.01$ vs. FSK.

Finally, HCN1 blockade by ivabradine occurs also, at least in part, when the channel is closed. If MEL55A behaves similarly, percentage blockade of $\mathrm{HCN} 1$ and $\mathrm{HCN} 2$ might be favored at less negative potentials, due to the combination of (i) preferential selectivity for these isoforms, (ii) blockade (also) of closed channels, and (iii) weak washout of the drug by current flowing through the pore. Instead, the blockade could be partially removed at more negative potentials, when large inward flow of $\mathrm{Na}^{+}$ions (and $\mathrm{K}^{+}$, depending on voltage) favors unblock of the channel. Due to its possible (patho)physiological implications for MEL55A or other compounds, this hypothesis deserves to be proved by appropriate testing in future experiments. 

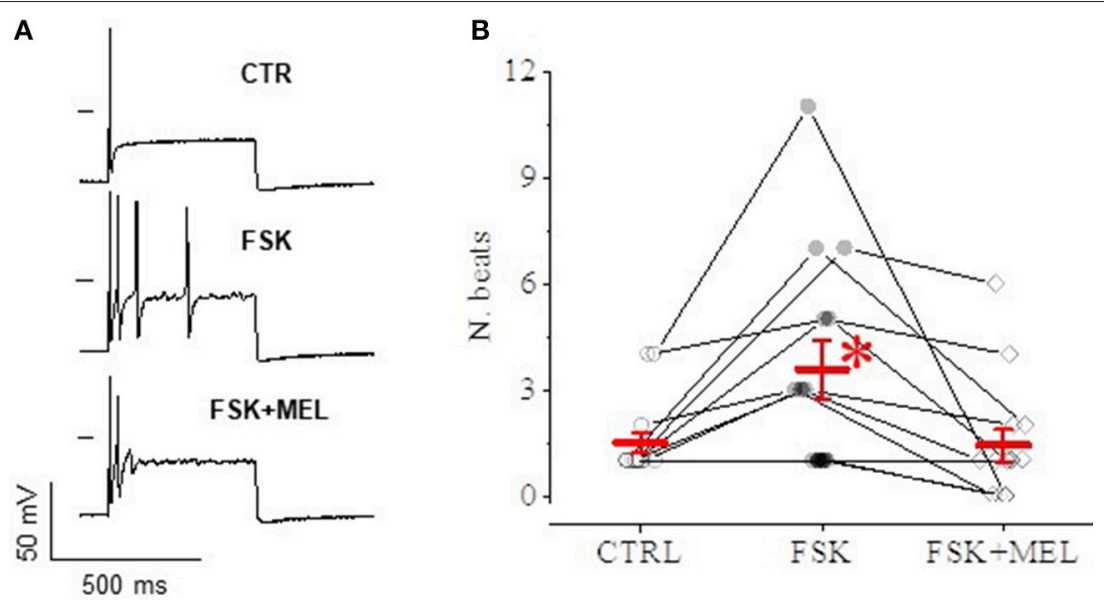

FIGURE 9 | Effect of MEL55A on neuron discharge. An example is reported in panel A: a depolarizing step evokes a single AP in control condition (A), followed by a series of APs after application of FSK (medium panel); $30 \mu \mathrm{M}$ MEL55A on top of FSK reduces the number of APs (lower panel). (B) shows number of beats for individual cells challenged with such an experimental protocol (points) and corresponding mean \pm S.E.M (in red) in $N=8$ cells; ${ }^{*} p<0.05$ vs. CTR and FSK + MEL by using Multiple $t$ test.

TABLE 1 | Anti-allodynic effect of MEL55A and EC18 in comparison with ivabradine on oxaliplatin-induced neuropathy (Cold plate test).

\begin{tabular}{|c|c|c|c|c|c|c|}
\hline \multirow[b]{2}{*}{ Treatment } & \multicolumn{6}{|c|}{ Licking latency (s) } \\
\hline & pretest & $15 \mathrm{~min}$ & $30 \mathrm{~min}$ & $45 \mathrm{~min}$ & $60 \mathrm{~min}$ & $75 \mathrm{~min}$ \\
\hline vehicle + vehicle & $23.2 \pm 1.0$ & $22.5 \pm 0.6$ & $22.8 \pm 0.9$ & $23.2 \pm 0.4$ & $21.9 \pm 1.1$ & $22.8 \pm 1.5$ \\
\hline vehicle + MEL55A 30 mg/kg & $22.8 \pm 1.9$ & $24.7 \pm 0.8$ & $23.5 \pm 1.3$ & $22.8 \pm 0.8$ & $24.1 \pm 0.8$ & \\
\hline vehicle + EC18 30 mg/kg & $21.6 \pm 1.2$ & $23.7 \pm 1.3$ & $24.5 \pm 0.8$ & $22.1 \pm 0.6$ & $20.1 \pm 0.9$ & \\
\hline vehicle + IVABRADINE 10 mg/kg & $22.65 \pm 1.3$ & $20.4 \pm 1.5$ & $22.6 \pm 1.1$ & $23.7 \pm 1.3$ & $22.4 \pm 0.9$ & \\
\hline oxaliplatin + vehicle & $13.8 \pm 1.1$ & $12.6 \pm 0.7$ & $14.3 \pm 0.5$ & $13.9 \pm 0.8$ & $13.7 \pm 0-7$ & $12.5 \pm 0.8$ \\
\hline oxaliplatin + MEL55A 30 mg/kg & $14.5 \pm 0.6$ & $19.4 \pm 0.8^{\star}$ & $21.9 \pm 0.9^{\star}$ & $18.5 \pm 0.8^{\star}$ & $15.5 \pm 0.9$ & $12.6 \pm 0.6$ \\
\hline oxaliplatin + EC18 30 mg/kg & $13.6 \pm 1.0$ & $12.2 \pm 0.9$ & $13.0 \pm 0.7$ & $14.2 \pm 0.5$ & $13.2 \pm 1.2$ & \\
\hline oxaliplatin + IVABRADINE 30 mg/kg & $13.8 \pm 1.4$ & $20.7 \pm 1.5^{\star}$ & $19.2 \pm 1.1^{*}$ & $17.4 \pm 0.9$ & $15.6 \pm 1.3$ & \\
\hline
\end{tabular}

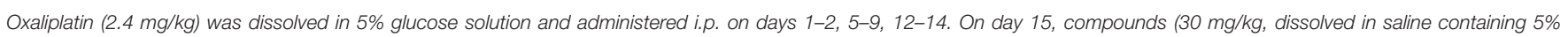

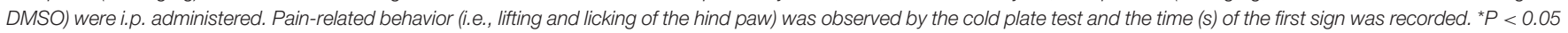
in respect to the oxaliplatin treated mice. Each value represents the mean of 12 mice performed in 2 different experimental sets.

The possibility to modulate DRG excitability by $I_{\mathrm{h}}$ blockade is not new and it has been proved in previous studies invivo and in-vitro. Administration of ZD7288 reduced $I_{\mathrm{h}}$ by $80 \%$; such an effect was accompanied by the suppression of the voltage sag, i.e., a time dependent depolarization consequent to injection of hyperpolarizing current due to $\mathrm{Na}^{+}$entry through HCN channels (Gao et al., 2012). A similar effect was achieved with ivabradine (Noh et al., 2014; Young et al., 2014), the only $I_{\mathrm{h}}$ blocker, specific bradycardic agent commercially available in angina and heart failure (Camici et al., 2016; Ponikowski et al., 2016; Psotka and Teerlink, 2016). Unfortunately, the exploitation of ivabradine as analgesic drug is precluded justly by its side (i.e., bradycardic) effect, a consequence of the lack of drug's selectivity toward HCN isoforms (or slight HCN4 selectivity, Bucchi et al., 2006) In this context, the possibility to exploit differences in $\mathrm{HCN}$ isoform expression among tissues seems attractive: indeed, HCN4, the most contributor for sinoatrial pacemaking (Moosmang et al., 2001; Stieber et al., 2004; Baruscotti et al., 2011), largely overexpressed in diseased ventricular tissue (Stillitano et al., 2008; Suffredini et al., 2012) seems to play a negligible role in neuronal excitability.

Several studies support the expression and role of HCN1 and HCN2 isoforms in DRG neurons in physiological conditions; nevertheless, the differential role of HCN subtypes in modulating pain is still a matter of debate (Acosta et al., 2012; Schnorr et al., 2014; DiFrancesco and DiFrancesco, 2015). The contribution of the HCN2 isoform in inflammatory pain is suggested by the involvement of cAMP-mediated pathways (e.g., by prostaglandin E2 receptor stimulation) and the efficacy of HCN2 silencing in relieving neuropathic pain (Emery et al., 2011, 2012; Resta et al., 2016). In our DRG neurons, forskolin, an adenylate cyclase activator, shifted current activation toward less negative potentials by $8-10 \mathrm{mV}$. Hence, the capability of MEL55A to reduce $I_{\mathrm{h}}$ amplitude and counteract the effect of forskolin on current activation is particularly relevant, suggesting that 
homomeric or heteromeric channels containing HCN2 subunits may represent targets of MEL55A blockade in hyperalgesia.

At the same time, several conditions such as nerve injury, antineoplastic agents and diabetes appear to increase $\mathrm{HCN} 1$ expression and function (Jiang et al., 2008; Tu et al., 2010; Descoeur et al., 2011). Different results have been also obtained depending on stress condition (acute vs. chronic pain) or stimulus (heat vs. mechanic hypersensitivity) (Schnorr et al., 2014). As a matter of fact, the relative expression of HCN1 and HCN2 isoforms is likely variable among neuron subsets, depending on size, location, and soundly reflecting different functions (Tibbs et al., 2016). Thus, a pharmacological tool aimed to target both HCN1 and HCN2 isoforms, but less potent on HCN4, might represent a suitable strategy in different settings.

To see if the $I_{\mathrm{h}}$-blocking properties of MEL55A observed in vitro could translate into a pharmacological effect in vivo, we tested the antihyperalgesic properties of this compound in a mouse model of oxaliplatin-induced neuropathy. Indeed, a rigorous pharmacological approach requires a previous pharmacokinetic assessment, which is not available at present and will be object of further studies. However, $30 \mathrm{mg} / \mathrm{Kg}$ MEL55A clearly showed a pain-relieving effect, which was longer-lasting when compared to the same dose of ivabradine. The significant antineuropathic effect of MEL55A could be explained, similarly to what observed with MEL57A, by $I_{\mathrm{h}}$ gainof-function caused by oxaliplatin treatment (Resta et al., 2018), possibly related to overexpression of the ancillary subunit MiRP1. When co-expressed in heterologous systems, this subunit is known to modulate both $\mathrm{HCN} 1$ and $\mathrm{HCN} 2$ isoforms by accelerating their kinetics (Yu et al., 2001; Qu et al., 2005). It is worth noting that, in the same conditions, the HCN4preferring agent EC18 (Del Lungo et al., 2012) lacked antiallodynic effect (Table 1), further suggesting that HCN4 plays a minor role in neuropathic pain (Emery et al., 2011; Resta et al., 2018).

\section{LIMITATIONS AND CONCLUSIONS}

At present, our results do not allow inferring that MEL55A represents a drug candidate; this aim was beyond the scope of this study. We must acknowledge several limitations, requiring further test: the lack of extensive pharmacodynamic (e.g., effect on channels different from HCN) and pharmacokinetics data and high concentrations used for our preliminary in-vivo proof

\section{REFERENCES}

Acosta, C., McMullan, S., Djouhri, L., Gao, L., Watkins, R., Berry, C., et al. (2012). HCN1 and HCN2 in rat DRG neurons: levels in nociceptors and non-nociceptors, NT3-dependence and influence of CFA-induced skin inflammation on HCN2 and NT3 expression. PLoS ONE 7:e50442. doi: 10.1371/journal.pone.0050442

Altomare, C., Terragni, B., Brioschi, C., Milanesi, R., Pagliuca, C., Viscomi, C., et al. (2003). Heteromeric HCN1-HCN4 channels: a comparison with native pacemaker channels from the rabbit sinoatrial node. J. Physiol. 549, 347-359. doi: 10.1113/jphysiol.2002.027698 of concept. However, present results are promising in view of drug design aimed to develop novel antinociceptive strategies and original tools able to discriminate the contribution of $\mathrm{HCN}$ isoforms in different pathophysiological conditions, which remains a challenging issue. The shortage of pharmacological agents able to treat neuropathic pain, a quite prevalent form of chronic pain, represents an increasingly medical burden (Finnerup et al., 2015). The availability of small molecules with selectivity toward HCN2 channels might represent a safe and effective strategy (Tsantoulas et al., 2016). In line with our recent findings (Resta et al., 2018), present data further support that, from a pharmacological point of view, this approach is affordable and deserves to be further exploited in more integrated models.

\section{AUTHOR CONTRIBUTIONS}

EC, MR, MD, FR, and RC: conception and design of experiments. $\mathrm{LD}, \mathrm{MD}$, and FR: collection, analysis, and interpretation of patch-clamp data. LDCM and CG: collection, analysis, and interpretation of behavioral data. VS, MD, and AL: design and analysis of molecular biology and immunohistochemistry. MM and MR: drug design and synthesis. LS, GM, MR, and EC: drafting the article or revising it critically for important intellectual content. All authors approved the final version of the manuscript.

\section{FUNDING}

This work was funded by grants from the University of Florence (ex 60\%) (MR); Ente Cassa di Risparmio di Firenze (2014.0319 to GM, 2013.0683 to LS); Normacor project (contract LSH $\mathrm{M} / \mathrm{CT} / 2006 / 018676$ to EC).

\section{ACKNOWLEDGMENTS}

We wish to thank Prof. Martin Biel (Ludwig-MaximiliansUniversität München, Germany) for providing stably transfected HCN1, HCN2 and HCN4 HEK293 cells.

\section{SUPPLEMENTARY MATERIAL}

The Supplementary Material for this article can be found online at: https://www.frontiersin.org/articles/10.3389/fphar. 2018.01252/full\#supplementary-material 
Bigagli, E., Luceri, C., De Angioletti, M., Chegaev, K., D’Ambrosio, M., Riganti, C., et al. (2018). New NO- and $\mathrm{H}_{2} \mathrm{~S}$-releasing doxorubicins as targeted therapy against chemoresistance in castration-resistant prostate cancer: in vitro and in vivo evaluations. Invest. New Drugs. 1-14. doi: 10.1007/s10637-018-0590-0

Bucchi, A., Baruscotti, M., and DiFrancesco, D. (2002). Current-dependent block of rabbit sino-atrial node I(f) channels by ivabradine. J. Gen. Physiol. 120, 1-13. doi: 10.1085 /jgp. 20028593

Bucchi, A., Tognati, A., Milanesi, R., Baruscotti, M., and DiFrancesco, D. (2006). Properties of ivabradine-induced block of $\mathrm{HCN} 1$ and $\mathrm{HCN} 4$ pacemaker channels. J. Physiol. 572, 335-346. doi: 10.1113/jphysiol.2005.100776

Camici, P. G., Gloekler, S., Levy, B. I., Skalidis, E., Tagliamonte, E., Vardas, P., et al. (2016). Ivabradine in chronic stable angina: effects by and beyond heart rate reduction. Int. J. Cardiol. 215, 1-6. doi: 10.1016/j.ijcard.2016.04.001

Cavaletti, G., Tredici, G., Petruccioli, M. G., Dondè, E., Tredici, P., Marmiroli, P., et al. (2001). Effects of different schedules of oxaliplatin treatment on the peripheral nervous system of the rat. Eur. J. Cancer 37, 2457-2463. doi: $10.1016 /$ S0959-8049(01)00300-8

Cerbai, E., Barbieri, M., and Mugelli, A. (1994). Characterization of the hyperpolarization-activated current, $\mathrm{I}_{\mathrm{f}}$, in ventricular myocytes isolated from hypertensive rats. J. Physiol. 481, 585-591.

Chaplan, S. R., Guo, H.-Q., Lee, D. H., Luo, L., Liu, C., Kuei, C., et al. (2003). Neuronal hyperpolarization-activated pacemaker channels drive neuropathic pain. J. Neurosci. 23, 1169-1178. doi: 10.1523/JNEUROSCI.23-04-01169.2003

Chen, S., Wang, J., and Siegelbaum, S. A. (2001). Properties of hyperpolarizationactivated pacemaker current defined by coassembly of HCN1 and HCN2 subunits and basal modulation by cyclic nucleotide. J. Gen. Physiol. 117, 491-504. doi: 10.1085/jgp.117.5.491

Del Lungo, M., Melchiorre, M., Guandalini, L., Sartiani, L., Mugelli, A., Koncz, I., et al. (2012). Novel blockers of hyperpolarization-activated current with isoform selectivity in recombinant cells and native tissue. Br. J. Pharmacol. 166, 602-616. doi: 10.1111/j.1476-5381.2011.01782.x

Descoeur, J., Pereira, V., Pizzoccaro, A., Francois, A., Ling, B., Maffre, V., et al. (2011). Oxaliplatin-induced cold hypersensitivity is due to remodelling of ion channel expression in nociceptors. EMBO Mol. Med. 3, 266-278. doi: $10.1002 / \mathrm{emmm} .201100134$

Di Cesare Mannelli, L., Lucarini, E., Micheli, L., Mosca, I., Ambrosino, P., Soldovieri, M. V., et al. (2017). Effects of natural and synthetic isothiocyanatebased $\mathrm{H}_{2} \mathrm{~S}$-releasers against chemotherapy-induced neuropathic pain: role of Kv7 potassium channels. Neuropharmacology 121, 49-59. doi: 10.1016/j.neuropharm.2017.04.029

Di Cesare Mannelli, L., Pacini, A., Bonaccini, L., Zanardelli, M., Mello, T., and Ghelardini, C. (2013). Morphologic features and glial activation in rat oxaliplatin-dependent neuropathic pain. J. Pain 14, 1585-1600. doi: 10.1016/j.jpain.2013.08.002

DiFrancesco, J. C., and DiFrancesco, D. (2015). Dysfunctional HCN ion channels in neurological diseases. Front. Cell Neurosci. 6:174. doi: $10.3389 /$ fncel.2015.00071

Emery, E. C., Young, G. T., Berrocoso, E. M., Chen, L., and McNaughton, P. A. (2011). HCN2 ion channels play a central role in inflammatory and neuropathic pain. Science 333, 1462-1466. doi: 10.1126/science. 1206243

Emery, E. C., Young, G. T., and McNaughton, P. A. (2012). HCN2 ion channels: an emerging role as the pacemakers of pain. Trends Pharmacol. Sci. 33, 456-463. doi: 10.1016/j.tips.2012.04.004

Finnerup, N. B., Attal, N., Haroutounian, S., McNicol, E., Baron, R., Dworkin, R. H., et al. (2015). Pharmacotherapy for neuropathic pain in adults: a systematic review and meta-analysis. Lancet Neurol. 14, 162-173. doi: 10.1016/S1474-4422(14)70251-0

Fukuda, J. (1985). Nerve cells of adult and aged mice grown in a monolayer culture: age-associated changes in morphological and physiological properties of dorsal root ganglion cells in vitro. Dev. Neurosci. 7, 374-394. doi: 10.1159/000 112304

Gao, L. L., McMullan, S., Djouhri, L., Acosta, C., Harper, A. A., and Lawson, S. N. (2012). Expression and properties of hyperpolarization-activated current in rat dorsal root ganglion neurons with known sensory function. J. Physiol. 590, 4691-4705. doi: 10.1113/jphysiol.2012.238485

Jafri, M. S., and Weinreich, D. (1998). Substance P Regulates $I_{h}$ via a NK-1 receptor in vagal sensory neurons of the ferret. J. Neurophysiol. 79, 769-777. doi: $10.1152 /$ jn.1998.79.2.769
Jiang, Y.-Q., Xing, G.-G., Wang, S.-L., Tu, H.-Y., Chi, Y.-N., Li, J., et al. (2008), Axonal accumulation of hyperpolarization-activated cyclic nucleotide-gated cation channels contributes to mechanical allodynia after peripheral nerve injury in rat. Pain 137, 495-506. doi: 10.1016/j.pain.2007.10.011

Li, J., and Baccei, M. L. (2014). Neonatal tissue injury reduces the intrinsic excitability of adult mouse superficial dorsal horn neurons. Neuroscience 256, 392-402. doi: 10.1016/j.neuroscience.2013.10.057

Melchiorre, M., Del Lungo, M., Guandalini, L., Martini, E., Dei, S., Manetti, D., et al. (2010). Design, synthesis, and preliminary biological evaluation of new isoform-selective f-current blockers. J. Med. Chem. 53, 6773-6777. doi: $10.1021 / \mathrm{jm} 1006758$

Momin, A., Cadiou, H., Mason, A., and McNaughton, P. A. (2008). Role of the hyperpolarization-activated current Ih in somatosensory neurons. J. Physiol. 586, 5911-5929. doi: 10.1113/jphysiol.2008.163154

Moosmang, S., Stieber, J., Zong, X., Biel, M., Hofmann, F., and Ludwig, A. (2001). Cellular expression and functional characterization of four hyperpolarizationactivated pacemaker channels in cardiac and neuronal tissues. Eur. J. Biochem. 268, 1646-1652. doi: 10.1046/j.1432-1327.2001.02036.x

Noh, S., Kumar, N., Bukhanova, N., Chen, Y., Stemkowsi, P. L., and Smith, P. A. (2014). The heart-rate-reducing agent, ivabradine, reduces mechanical allodynia in a rodent model of neuropathic pain. Eur. J. Pain 18, 1139-1147. doi: $10.1002 / j .1532-2149.2014 .00460 . x$

Papp, I., Holló, K., and Antal, M. (2010). Plasticity of hyperpolarizationactivated and cyclic nucleotid-gated cation channel subunit 2 expression in the spinal dorsal horn in inflammatory pain. Eur. J. Neurosci. 32, 1193-1201. doi: 10.1111/j.1460-9568.2010.07370.x

Ponikowski, P., Voors, A. A., Anker, S. D., Bueno, H., Cleland, J. G. F., Coats, A. J. S., et al. (2016). 2016 ESC Guidelines for the diagnosis and treatment of acute and chronic heart failure. The Task Force for the diagnosis and treatment of acute and chronic heart failure of the European Society of Cardiology (ESC). Eur. Heart J. 37, 2129-2200. doi: 10.1093/eurheartj/ehw128

Psotka, M. A., and Teerlink, J. R. (2016). Ivabradine: role in the chronic heart failure armamentarium. Circulation 133, 2066-2075. doi: 10.1161/CIRCULATIONAHA.115.018094

Qu, J., Kryukova, Y., Potapova, I. A., Doronin, S. V., Larsen, M., Krishnamurthy, G., et al. (2005). MiRP1 modulates HCN2 channel expression and gating in cardiac myocytes. J. Biol. Chem. 279, 43497-43502. doi: 10.1074/jbc.M405018200

Resta, F., Masi, A., Sili, M., Laurino, A., Moroni, F., and Mannaioni, G. (2016). Kynurenic acid and zaprinast induce analgesia by modulating HCN channels through GPR35 activation. Neuropharmacology 108, 136-143. doi: 10.1016/j.neuropharm.2016.04.038

Resta, F., Micheli, L., Laurino, A., Spinelli, V., Mello, T., Sartiani, L., et al. (2018). Selective HCN1 block as a strategy to control oxaliplatin-induced neuropathy. Neuropharmacology 131, 403-413. doi: 10.1016/j.neuropharm.2018.01.014

Sartiani, L., Mannaioni, G., Masi, A., Romanelli, M. N., and Cerbai, E. (2017). The hyperpolarization-activated cyclic nucleotide-gated channels: from biophysics to pharmacology of a unique family of ion channels. Pharmacol. Rev. 69, 354-395. doi: 10.1124/pr.117.014035

Savalieva, I., and Camm, A. J. (2006). Novel $\mathrm{I}_{\mathrm{f}}$ current inhibitor ivabradine: safety considerations. Adv. Cardiol. 43, 79-96. doi: 10.1159/000095430

Schnorr, S., Eberhardt, M., Kistner, K., Rajab, H., Käer, J., Hess, A., et al. (2014). HCN2 channels account for mechanical (but not heat) hyperalgesia during long-standing inflammation. Pain 155, 1079-1090. doi: 10.1016/j.pain.2014.02.006

Stieber, J., Hofmann, F., and Ludwig, A. (2004). Pacemaker channels and sinus node arrhythmia. Trends Cardiovasc. Med. 14, 23-28. doi: $10.1016 /$ j.tcm.2003.09.006

Stillitano, F., Lonardo, G., Zicha, S., Varro, A.,Cerbai, E., Mugelli, A., et al. (2008). Molecular basis of funny current (If) in normal and failing human heart. J. Mol. Cell. Cardiol. 45, 289-299. doi: 10.1016/j.yjmcc.2008.04.013

Suffredini, S., Stillitano, F., Comini, L., Bouly, M., Brogioni, S., Ceconi, C., et al. (2012). Long-term treatment with ivabradine in post-myocardial infarcted rats counteracts f-channel overexpression. Br. J. Pharmacol. 165, 1457-1466. doi: 10.1111/j.1476-5381.2011.01627.x

Tibbs, G. R., Posson, D. J., and Goldstein, P. A. (2016). Voltage-gated ion channels in the PNS: novel therapies for neuropathic pain? Trends Pharmacol. Sci. 37, 522-542. doi: 10.1016/j.tips.2016.05.002 
Tsantoulas, C., Mooney, E. R., and McNaughton, P. A. (2016). HCN2 ion channels: basic science opens up possibilities for therapeutic intervention in neuropathic pain. Biochem. J. 473, 2717-2736. doi: 10.1042/BCJ201 60287

Tu, H., Zhang, L., Tran, T. P., Muelleman, R. L., and Li, Y. L. (2010). Diabetes alters protein expression of hyperpolarization-activated cyclic nucleotidegated channel subunits in rat nodose ganglion cells. Neuroscience 165, 39-52. doi: 10.1016/j.neuroscience.2009.10.002

Yao, H., Donnelly, D. F., Ma, C., and LaMotte, R. H. (2003). Upregulation of the hyperpolarization-activated cation current after chronic compression of the dorsal root ganglion. J. Neurosci. 23, 2069-2074. doi: 10.1523/JNEUROSCI.23-06-02069.2003

Young, G. T., Emery, E. C., Mooney, E. R., Tsantoulas, C., and McNaughton, P. A. (2014). Inflammatory and neuropathic pain are rapidly suppressed by peripheral block of hyperpolarisation-activated cyclic nucleotide-gated ion channels. Pain 155, 1708-1719. doi: 10.1016/j.pain.2014. 05.021
Yu, H., Wu, J., Potapova, I., Wymore, R. T., Holmes, B., and Zuckerman, J., et al. (2001). MinK-related peptide 1: a $\beta$ subunit for the HCN ion channel subunit family enhances expression and speeds activation. Circ. Res. 88, e84-e87. doi: $10.1161 /$ hh1201.093511

Conflict of Interest Statement: The authors declare that the research was conducted in the absence of any commercial or financial relationships that could be construed as a potential conflict of interest.

Copyright (c) 2018 Dini, Del Lungo, Resta, Melchiorre, Spinelli, Di Cesare Mannelli, Ghelardini, Laurino, Sartiani, Coppini, Mannaioni, Cerbai and Romanelli. This is an open-access article distributed under the terms of the Creative Commons Attribution License (CC BY). The use, distribution or reproduction in other forums is permitted, provided the original author(s) and the copyright owner(s) are credited and that the original publication in this journal is cited, in accordance with accepted academic practice. No use, distribution or reproduction is permitted which does not comply with these terms. 